\title{
Mental Health Disorders in Livestock Producers: The Suicide Phenomenon may the Rural Veterinary Practitioner Play a Role?
}

Jos Noordhuizen*

Department of Agriculture \& Veterinary Science, Former Diplomat of ECBHM and ECVPM, Europe

*Corresponding author: Jos Noordhuizen, Former Diplomat of ECBHM and ECVPM, Europe.

Received Date: October 17, 2019

Published Date: November 01, 2019

\section{Introduction}

Mental health problems in general, and suicides in particular, seem to have become part of everyday life these recent years. On an annual basis, $27 \%$ of Americans, for example, face such a problem; the average American would have a $47 \%$ probability of suffering from such a problem in his or her life [1].

A mental health disorder is a physical disease of the brain that causes disorders of thinking, behavior, energy allocation and emotions. There are two groups of mental health disorders:

- Anxiety disorders (post-traumatic stress disorder; obsessive-compulsive disorder; anxiety disorder; panic disorder; phobia).

- $\quad$ Mood disorders (depression; bipolar depression). Both groups can lead to suicide [2].

The suicide rate among farmers is increasing every year. In the United States, the rate has increased by $13 \%$ in recent years. The suicide rate among farmers is twice as high as in the average population. In addition, of the three reported homicides, two appeared to be suicides. Sometimes suicides are reported as "farm accidents". In Australia, the frequency of suicides is reported as one every four days; in the United Kingdom, one per week; in France, two per day.

In France, this rate is $12.6 \%$ higher than the population average [3]; it was 605 people in 2015, of whom 274 were over 65 years old; 4 out of 5 people were men. Between 2007 and 2011 there were 150 of them. Cattle and milk producers were particularly affected. These are livestock farmers but also employees. In addition, 109 women (farmers and employees) had committed suicide. Among people over 65 years of age, especially those with a disability pension (15\%) and with a supplementary pension (57\%) were affected. All these figures are very alarming.

The number of suicides has increased worldwide since the agricultural economic crisis of the 1980s [4]. This crisis has resulted in a collapse of market prices, forced loan repayments and a doubling of interest rates. Net farm income in the United States has declined by $50 \%$ since 2013 [4]. As a result, farmers were forced to liquidate their land, buildings and/or livestock. In France, the end of milk quotas led to a loss of control by the farmer over the price of milk; it was now the world market that dictated the price. In addition, supermarkets contribute a lot by lowering prices for farmers. And if they did not accept, they were eliminated from the supply system. Free trade and now CETA seem increasingly disastrous for the French agricultural sector [5].

It has been said that, for farmers, the loss of agricultural land affects the soul and heart more deeply than a single human death. In fact, agriculture and livestock can become a contradictory process: farmers want to produce and provide food to the community, while at the same time, when they are no longer able to do so, they become desperate [4].

This paper examines the context of distress and depression among livestock producers who often lead to suicide, some coping strategies to deal with these disorders, and the role that veterinarians could play in rural areas with respect to livestock producers' suicide risks.

\section{Reasons for Farmer's Distress}

Livestock farming has evolved from a purely family farm, often on a small scale and multi-species, to a more entrepreneurial enterprise. First, livestock farms have expanded due to the reduction 
in margins between production costs and income; second, new technologies have entered the livestock sector, such as milking machines, robotic milking, sophisticated harvesting machines and management computers. In recent years, the administrative burden has increased due to animal health requirements, quality control, manure and waste management, and environmental restrictions.

In parallel with these developments, the degree of stress has also increased due to uncertainty about the price of milk, the costs of purchased food, production costs in general and labor costs. Rural populations earn less than urban communities; their overall health is poorer and access to medical and mental health care is often sporadic. Many factors associated with livestock are beyond the control of the farmer; this contributes to the uncertainty and distress of the farmer [4]. In addition, small rural communities have lost inhabitants over the years, making life less interesting for those who have stayed and limiting people's encounters, causing some stress in itself, while access to medical and/or psychological assistance is difficult. Moreover, it is not easy for a farmer to open up to a stranger such as a psychologist in town. Many farmers can cope with these problems, while others experience distress and depression, which makes them unable to cope adequately.

Table 1: A non-exhaustive list of feelings of farmers already in a state of depression.

\begin{tabular}{|c|}
\hline I feel torment in my head almost every day \\
\hline I can't think straight anymore \\
\hline I feel kind of paralyzed \\
\hline I have real problems sleeping \\
\hline I am very stressed when the harvest season begins \\
\hline I have more and more doubts about my decisions \\
\hline I don't want to answer the phone anymore, they bother me \\
\hline I can't handle these big debts \\
\hline I don't want to see all these invoices anymore \\
\hline I work 80 hours a week and there is still no solution \\
\hline I don't even have money for the dentist or a therapist \\
\hline I panic every time a late frost puts my crops at risk \\
\hline I know I'm unhappy married, but what can I do? \\
\hline
\end{tabular}

Source: [14] presents a non-exhaustive list of various feelings expressed by farmers already depressed.

In rural areas, it is not uncommon for farms and livestock operations to be rather isolated from each other. Family members are rejected by themselves, while contact with colleagues is becoming increasingly rare [6]. The backbone of the farm family requires good communication on all matters that have a positive or negative impact on the operation. Unfortunately, this does not happen everywhere and not always. The farmer must make all decisions on his own, without the technical or moral support of his neighbors or professionals, and with a high degree of uncertainty. Professional advice can be received, but it does not always guarantee the best cost-benefit ratio. This can lead to increased uncertainty and when the decision leads to undesirable results, the farmer may fall into a negative downward spiral. And then, who should he turn to? Most often, a farmer does not want to disturb family members with the problems he is experiencing, stating that "it is already difficult enough as it is", or that he cannot find professional support (Table 1).

The most relevant symptoms for people with depression are lack of self-confidence, loss of interest in activities they used to enjoy, loss of appetite, easy fatigue, loss of memory, feeling out of energy, tears, nervousness or irritability, complete silence. The combination of distress factors or mental disorders is commonly referred to as "stigmatization". Stigma is a container term, which means that there are many factors at play, which makes a solution difficult. In Annex 1 there is an overview presented with the different phases of burn-out, a phenomenon associated with depression. Various risk factors for depression have been reported in the literature (Table 2).

Table 2: Overview of relevant risk factors for depression.

\begin{tabular}{|c|}
\hline The presence of a physical health problem (e.g. disability) \\
\hline Problems in a relationship (e.g. marriage) \\
\hline Problems in employment situations \\
\hline Social isolation (church; community; family) \\
\hline Significant changes in living conditions (e. g. divorce) \\
\hline Pregnancy and childbirth \\
\hline Alcohol and/or drug problems \\
\hline (Threat of) Financial losses and over-indebtedness \\
\hline (Threat of) Loss of the farmland and/or farm buildings (debts) \\
\hline Obstacles or refusal to obtain professional help (taboo) \\
\hline Access to lethal means (vehicle; weapons; ropes) \\
\hline I panic every time a late frost puts my crops at risk \\
\hline I know I'm unhappy married, but what can I do? \\
\hline
\end{tabular}

Source: $[14,3]$ provides an overview of the risk factors considered most relevant.

There are warning signs that may indicate an imminent suicide. Some examples are listed in [3] (Table 3).

Table 3: Some examples of warning signs preceding a suicide.

\begin{tabular}{|c|}
\hline Soon I won't be bothering anyone anymore \\
\hline It would be much better for everyone if I wasn't there. \\
\hline I don't belong here; I'm useless \\
\hline I know what I have to do now \\
\hline I can't take it anymore \\
\hline
\end{tabular}

Source: $[14,3]$ provides an overview of the risk factors considered most relevant.

Among the agricultural world there is a taboo on this suicide problem. They don't really want to talk about that; it is considered a shame. They suffer in silence, sometimes even in the family. Honor is broken or there is a sense of guilt Truck, 2019. There is a lack of recognition from the general public. What remains in the memory is the history of overdosing pesticides as if all farmers are crooks. The general public no longer recognizes the moral and material value of the work of farmers. But people are willing to spend a few days off in the countryside to take a rest.

People who are at the lowest risk for suicide are characterized as follows: those with a well-developed social network; those with good reasons for living; those with responsibility for young children; 
those who are linked to religiosity; those who are extroverted and optimistic; and those who can cope well with different problems [7].

\section{Some coping strategies}

A strong, hard, cheerful or friendly character has nothing to do with a farmer's degree of susceptibility to mental disorders such as burn-out and depression. It is usually a question of knowing what coping strategies a particular farmer has at his disposal to deal with his distress or depression. Some coping strategies focus on the problem itself, while others are much more emotionally focused. It seems that problem-focused adaptation can reduce the emotional effects of depression.

Focusing on the problem often requires the help of a technical professional for problems related to the farm, herd or machinery. For example, a farm suffers serious calf losses due to complex health problems. In this case, the veterinarian can help the farmer solve this problem through a veterinary protocol approach to herd health [8]. Dealing with emotional problems is more complex; in fact, it is a multifactorial and additive model. The more emotions from different origins, the more difficult it is to solve this problem.

People with poor mental health and high stress appear to use less adaptive coping strategies, such as running away from the problem, being cautious about the problem, using instrumental actions to solve the problem, remaining stoic and seeking help. The various coping efforts all affect a person's mental health status [9]. On the Internet, there are many approaches and advice sites to deal with the problem, most of them in the United States, Australia and the United Kingdom. One expert name that appears all the time is Dr. Michael Rossman. In France, there is the Agri'Ecoute (MSA) and the Association Solidarité Paysans, but this does not necessarily solve the problems. Perhaps the distance from these authorities is too great and impersonal, and it is a taboo to talk about it among the farmers themselves.

There are examples that point to something very important. Camion 2019 tells the story of a pig farmer in Normandy whom he interviewed for the French Journal Le Figaro. Later this farmer told him that talking for a long time to someone who took his time to listen to him was like therapy for the farmer and probably prevented him from committing suicide.

\section{What can you do to help people with serious, potentially suicidal distress problems?}

The most important thing to do is to talk to this person. Apparently, the affected people slowly turn to themselves (introverted) and stop communicating, even with their own family members. Communication is the key. It should be noted that there is a significant difference between a single farm manager and the distribution of diversified farm management roles among people. The first can hinder appropriate communication; the second requires functional communication [10].

Show interest in their feelings and do not judge them $[11,12]$. The second important issue is to set aside time for this person and avoid any distractions. When addressing such a person, avoid using questions that can be answered with a "yes" or "no". Ask open-ended questions, starting with "what; when; when; where; why; how". The latter invite the person much more to open up and elaborate. Most certainly, when the person wants to talk, let him talk freely, do not interrupt or push them (they could talk a lot, or they could talk a little; just let them talk). Never put pressure on him; this process requires trust and courage.

Do not try to make a diagnosis or agree with their feelings (you are not professionally qualified). Do not make assumptions or advise him. The goal is to let him get rid of all the pressure points in his mind by talking to someone who seems to be interested in him.

Is there a family problem? If he agrees, you can talk to family members and hear their views; at the same time, you can inform them of what you think is happening to the farmer (father, brother, uncle). In the event that there is no family communication on a certain farm, you could use a worksheet that focuses on creating family communication meetings where, for example, the division of tasks and responsibilities could be assigned to family members. Annex 2 gives an example of some basic rules for family meetings.

Talking about well-being: what does he mean by that? What elements are part of his well-being? For example, exercise (cycling, walking, driving a tractor), eating a healthy diet, taking a break. There are inventory sheets to find out about their ideas on wellness (Annex 3).

Listen carefully to what he says. Repeat by summarizing his sentences to show that you want to understand. Respect their feelings. You don't have to agree with him. Offer your help to get professional support if they want it, especially if you have the idea that they may become suicidal. Provide information such as brochures from organizations that can help you. Never take control; after all, it is he who decides. Know your own limits. Act if the problem appears to be medical (e.g., injuries) or if there is immediate danger based on precursor signals (suicide). Let him know that you are available for him at all times.

Apparently, the people who commit suicide decided to do so in the last 5 minutes before the act. But there are warning signs see Table 3. Remember that for someone who really committed suicide, there were three failed suicide attempts.

\section{A potential role for the veterinarian in rural areas?}

Rural veterinary practitioners generally have close links with their Farmers and often even with family members. This allows them to have fairly easy access to these people. In general, the veterinarian knows what is going on, both technically on the farm and in the herd and socio-psychologically in the family. This gives the veterinarian a great advantage over external doctors and psychologists in initiating conversations with them, even on sensitive topics such as distress, depression and possible suicide (Figure 1).

Of course, one could object and say that "I was not trained for such things", which is true. On the other hand, it could be 
very humane and humanistic to enter this field and make some efforts Figure 1. This also includes the farmer's family; perhaps the practitioner is able to establish communication with family members for the affected person. When it works, it's very rewarding for the person to have someone who really cares about him, and for the practitioner because you may have saved a life.

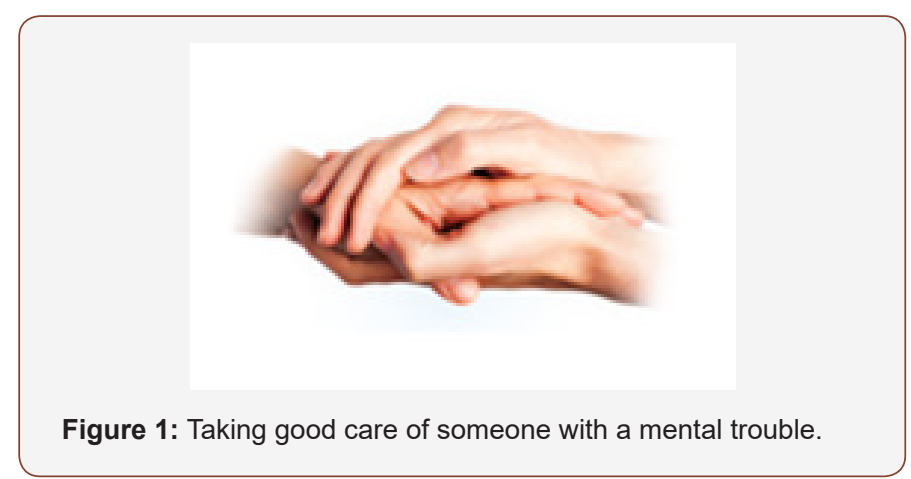

In this context, it may be useful to read what is written in Science \& Vie magazine (Issue 1225, October 2019) about placebo effects. The following lines provide a short summary. Contrary to what was thought before that the placebo gave a purely psychological effect, it has been shown several times in a large series of experiments, including brain imaging, that the placebo effect is more at the biological level and at the level of neural networks in the brain. The prefrontal cortex plays a major role, next to other cerebral centers. Placebo can trigger the production of specific molecules in the body, such as endorphins and endocannabinoids (stimulating the production of dopamines and a decrease in prostaglandins) that occupy the same receptors as products such as morphine and cannabis respectively. Thus, they can play a pain-relieving and wellness role respectively. So far there are several medical indications for using placebos, e. g. depression; post-traumatic stress disorder; Parkinson's disease; migraine; pain. There are no placebo results in patients with Alzheimer's........ because in this case the prefrontal cortex is apparently damaged!

What are the factors that best contribute to an optimal placebo effect? These are: trust; power of speech and the right choice of words; empathy; attention; positive and optimistic character; motivation; cognitive control; suggestibility; awareness of oneself and one's environment. This is called a "conscious expectation". There are signals that can already initiate this good sensitivity, such as the colour of pills (red or yellow = stimulating; blue or green = soothing), an odour (as in a veterinary clinic), white doctors' coats. People who are anxious or pessimistic show a much smaller and perhaps even negative placebo effect. But there is also an "unconscious learning". This means that some conditioning may occur (e. g. the Pavlov's dog) in humans but also in animals. The human body needs four days to learn and then trigger the placebo effects. For example, after several days of treatment with a drug, the body has learned that it must produce endocannabinoids (after treatment with aspirins or Kerolac) or endorphins (after treatment with morphine). The placebo effect is even there when the patient knows that the pill does not contain any active molecules! What we could philosophize in this article is that - by providing an environment that includes the factors mentioned above - we are more or less able to trigger a placebo effect in the potentially suicidal person with whom we are talking, and thus contribute to improving their situation.

In Annex 4, several ideas are summarized to support an individual or family who has experienced a traumatic event, such as suicide of a family member [13].

\section{Conclusion}

The incidence of suicide among farmers is very high. Apparently, there are many constraints in livestock farming but especially from outside (free trade; CETA; agricultural policy; big supermarkets) that take livestock farmers in hand. This is associated with world market, product prices, the flexibility of banks to provide credit and public opinion. To have a salary at the minimum wage level, for example, the price of milk should be 0.44 euros per liter in France; they are very far from this level and nobody is doing anything about it. It gives the impression of perversity.

It appears that those who committed suicide were not detected in time, did not communicate appropriately and/or were unable or unwilling to seek or find professional help. Mental health disorders such as distress, depression and suicide are complex because they are multifactorial. Some basic knowledge can help to report changes in behavior, communication and performance in a timely manner. As mentioned above, if professional help is not easily available, family members could play a role in reducing the distress pressure on the person concerned. Communication is essential here. But caution must be exercised with this communication; that is why some guidelines have been provided here. Note that body language, tone of voice and use of language are just as important as the topics you talk about when you talk to this person. Sometimes the person has a preference to talk to $\mathrm{X}$ and not Y. Adaptation strategies can be learned, but these trainings must be practical and accessible to all and delivered on site. In France -according to the author's knowledge- this type of training does not exist, at least not for farmers.

The position of the veterinary practitioner in rural areas is highly strategic. He is close to the farm and the farmer, and often even to the family. This allows the practitioner to easily access the farm, even in case of problems, distress and depression, and take on the role of a coach [14-16]. This is especially important in a situation where there is a taboo in the community. The next question is whether or not the practitioner wants to be involved in these activities to relieve the daily pain of the affected farmer. He is not required to do so and does not have the professional training to solve the problem. On the other hand, the practitioner should ask himself whether his neutral position allows and facilitates an open conversation in which the person concerned can express himself fully, just from a human and humanistic point of view. The person especially wants someone reliable to be there and who wants to listen (see the example of the pig farmer above). This can open up a process for livestock farming, where family members can also play their part, as well as professional support. The practitioner 
should invest time and effort to initiate this process, then others (professionals) can take over. During this process, the practitioner is always there and can always visit the farm.

\section{Acknowledgment}

None.

\section{Conflict of interest}

No conflict of interest.

\section{References}

1. AADA (2019) Anxiety and Depression Association of America. Nonprofit organization, USA.

2. Penn DL (1998) The stigma of severe mental illness: some potential solutions for a recalcitrant problem. Psychiatr Q 69(3): 235-247

3. MSA (2019) Mutualité Sociale Agricole, France.

4. (2018) The Guardian, USA.

5. Campion E (2019) Why is there a farmer suicide every two days in France? Europe.
6. Jared G (2019) Center of Disease Control. Atlanta, USA.

7. Turecki G, Brent DA (2016) Suicide and suicial behavior, The Lancet 387(10024): 1227-1239.

8. Noordhuizen JPTM (2012) Dairy herd health and management. Context Products, Packington, UK.

9. Aldwin CA, Revenson TA (1987) Does coping help? A reexamination of the relation between coping and mental health. J Pers Soc Psychol 53 (2) 337-348.

10. OK GOV (2019) A planning guide and workbook for Ag families, Ppt 95112.

11. (2019) Mental health, UK.

12. (2019) Mental health, USA.

13. Fetsch RJ, Jacobsen B (2007) Ten tips for successful family meetings. USA.

14. Noordhuizen JPTM, Edmonson P (2019) Arranging a conflict on a dairy farm, The veterinarian as a process coach. Animal Husbandry, Dairy and Veterinary Science.

15. Merat MC (2019) The true secrets of the placebo effect, Ppt 70-75.

16. (2019) Placebo toward a medical revolution. Science \& Vie, pp 76-80. 